\title{
Original Research \\ Transnational Comparison: A Retrospective Study on e-Health in Sparsely Populated Areas of the Northern Periphery
}

Anne Roberts, B.A. (Hons), ${ }_{1}^{1}$ Jarmo Reponen, M.D., ${ }^{2}$ Ulla-Maija Pesola, M.Sc., ${ }^{3}$ Eva Waterworth, Ph.D., ${ }^{3}$ Frank Larsen, M.Sc., ${ }^{4}$ Minna Mäkiniemi, Ph.D., ${ }^{5}$ David James Heaney, B.A., M.Sc., ${ }^{1}$ Mary Wakeling, B.A. (Hons), ${ }^{1}$ Anne McFarlane, Ph.D., ${ }^{6}$ Ilkka Winblad, M.D., Ph.D., ${ }^{2}$ and Bente Christensen, Nurs. Sci. ${ }^{4}$

${ }^{1}$ Centre for Rural Health, University of Aberdeen, Inverness, United Kingdom.

${ }^{2}$ FinnTelemedicum and Raahe Hospital, University of Oulu, Oulu, Finland.

${ }^{3}$ Department of Informatics, Umea University, Umeå, Sweden.

${ }^{4}$ Norwegian Centre for Integrated Care and Telemedicine, University Hospital of North Norway, Tromsø, Norway.

${ }^{5}$ Northern Ostrobothnia Hospital District, Oulu University, Oulu, Finland.

${ }^{6}$ Department of General Practice, National University of Ireland, Galway, Ireland.

\begin{abstract}
Healthcare delivery in the northern periphery of Europe is challenged by dispersed populations, geographical complexities (including mountainous terrain and inhabited islands), ageing populations, and rising patient expectations. It is challenged further by variations in transport networks and information communication technology infrastructure. This article provides an overview of e-health development across the northern periphery areas of four northern European countries (Finland, Sweden, Norway, and Scotland) by summarizing the outcomes of a mixed methods e-health mapping exercise and subsequently identifying service needs and gaps. A total of 148 applications, with a range of applied ehealth solutions, were identified and the findings have promoted the sharing and transfer of e-health innovation across the four countries. The supporting telecommunications infrastructure and development of innovative telemedicine appear slower in sparsely populated areas of Scotland in comparison to its northern peripheral counterparts. All four countries have, however, demonstrated a clear commitment to the development of e-health within their remote and rural regions.
\end{abstract}

Key words: e-health, telehealth, telemedicine

\section{Introduction}

he northern periphery region extends across the sparsely populated areas of northern Europe, including Scotland, Norway, and Sweden, most of Finland, and all of Greenland, Iceland, and the Faroe Islands. ${ }^{1}$ This article includes the sparsely populated northern periphery regions of four countries: Norway, Sweden, Scotland, and Finland. The healthcare systems in these countries are comparable, mainly tax-funded, with the welfare states controlling overall policies of health and medical services. In Finland, the organization of public health services covers $85 \%$ of health services, $15 \%$ being privately funded. ${ }^{2}$ These countries share similarities in terms of geographical challenges and remoteness from healthcare services. Social and cultural features are also comparable; a key societal challenge is the ageing society, with older people representing an increasing part of the population ${ }^{3}$ and an associated incidence of chronic diseases and depression. ${ }^{4}$ Figure 1 displays a map of the northern periphery areas and boundaries.

In recent years, national health authorities have begun to focus on the development of e-health services as a response to remote and rural healthcare delivery challenges. ${ }^{5}$ It has been argued that health service telemedicine projects often develop sooner in countries, where geographical challenges impact upon healthcare delivery. ${ }^{6}$ The northern periphery countries of Scotland, Norway, Finland, and Sweden have all made commitments to the development of national e-health strategies. ${ }^{2,7-9}$

"E-health" is a relatively new and interchangeable term, ${ }^{10}$ encompassing a broad range of definitions. Common features among multiple e-health descriptions have been identified as "health" and "technology." 11 Here, we define "e-health" as an umbrella term for the use of information communication technology in patient care, including both management systems such as electronic patient records (EPRs) and clinical communication systems such as telemedicine or telehealth applications.

This article describes the extent of e-health development in the sparsely populated areas of four northern periphery countries. Data were extracted from a wider project, part funded by the European Union (European Regional Development Fund) through the Northern Periphery Program (NPP). The overall project aims to enhance the provision of accessible health services within sparsely populated areas of northern Europe through the sharing and transfer of e-health knowledge and solutions.

\section{Methods}

To document the status of e-health across the northern peripheral areas of these four participating countries, a mapping exercise was designed. This was conducted between June and September 2008 and a portfolio of established e-health applications was produced. ${ }^{12}$ Two levels of e-health developments were identified during the mapping: national, which included the northern periphery, and local e-health activity within the regions. A research team from each country 


\section{ROBERTS ET AL.}

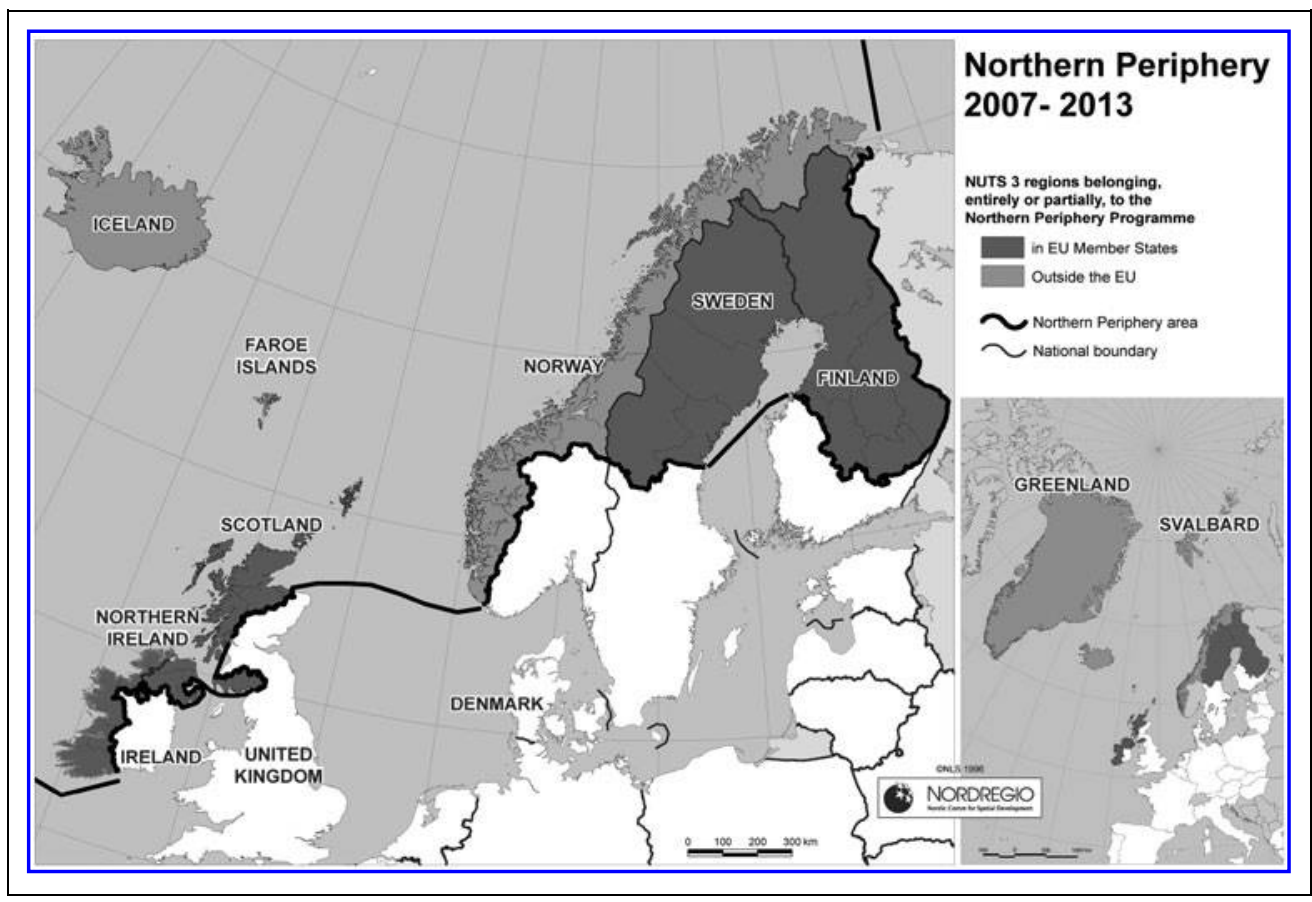

Fig. 1. Map of the northern periphery borders.

these help to provide an overview of the status of e-health in sparsely populated regions of these European countries and identify examples of best practice.

\section{TELECOMMUNICATIONS INFRASTRUCTURE}

A basic requirement for a reliable e-health environment is sufficient digital infrastructure. This section reviews structures across the northern peripheral areas of the four countries in the study.

Sweden. The telecommunications infrastructure in Sweden is advanced, with good digital infrastructure, reliable broadband, and mobile facilities. Such telecommunications support e-health applications even in Sweden's remote areas. The Swedish research team chose to demonstrate the county council area of Västerbotten in the north of the

contributed to the mapping exercise by utilizing the most appropriate qualitative research methods to collate examples of e-health solutions. This comprised a combination of face-to-face and telephone interviews with owners of e-health applications, supplemented by desk-based research. In addition, Finland mapped provision of their healthcare services using a structured online survey questionnaire e-mailed to 91 companies across the country (and e-mailed again to capture a high response rate as possible).

The research teams collaboratively devised a generic e-health checklist as a template to detail each innovation and to document comparable information. Checklists were only completed for those ehealth applications that were currently active, whose existence had been verified and/or had been evaluated regarding technical quality, diagnostic quality, user satisfaction, and/or cost effectiveness.

Table 1 illustrates the checklist that was developed and used to detail e-health activity.

In addition to the completion of the e-health checklists, each research team undertook manual searches of relevant e-health technical and policy documentation (including publically available online resources and paper document reviews) to develop a clearer understanding of the supporting telecommunications infrastructure in each of the four northern European countries.

\section{Results}

The results below document the outcome from the e-health mapping exercise. A total of 148 e-health solutions were identified across the four countries. Two key topics are discussed: telecommunications infrastructure and e-health development. Together country as an example, delivering healthcare to 250,000 inhabitants. This county has a separate, highly secure regional computer network called alternating current (AC)-net over and above integrated services digital network (ISDN) connections, providing the institutions of Västerbotten County with high-speed, secure user access and enables fast and secure communication between all parts of the county. There is also a national, highly secure network Sjunet, which connects all healthcare organizations within the country. In 2008, 99\% of the Swedish population had access to the network. In Västerbotten's rural areas, $\sim 98 \%$ of the population has access to a fast Internet connection ${ }^{13}$ and all healthcare centers in this area have videoconference equipment installed. At the time of this study, 90\% of the country's municipal councils were familiar with the national strategy for e-health; the majority had adopted the strategy. ${ }^{9}$

Finland. In Finland, there is no dedicated telecommunication network for healthcare, but healthcare providers purchase connections from commercial providers. They provide secure, high-bandwidth connections. Even in the most sparsely populated northern Lapland, the bandwidth is wide enough for image transmission and centralized health archiving. Although the connections between organizations and healthcare units are well established, not all the citizens in remote areas enjoy the broadband network to their homes. ${ }^{2}$ The Finnish government has published an agenda, which will ensure a broadband availability to all the citizens, via either wired or wireless means (e.g., WiFi). Currently, the mobile phone network coverage is comprehensive across Finland, with Global System Mobile or General Packet Radio Service 3G radio technology 


\begin{tabular}{|c|c|}
\hline \multicolumn{2}{|c|}{ CHECKLIST OF E-HEALTH SERVICES } \\
\hline Owner & \\
\hline \multicolumn{2}{|l|}{ Developer } \\
\hline \multicolumn{2}{|l|}{ Country of origin } \\
\hline \multirow[t]{4}{*}{ Cost of the service } & Start-up costs \\
\hline & Maintenance costs \\
\hline & Operational costs \\
\hline & Who does the work? \\
\hline \multirow[t]{2}{*}{ Target group and area } & Who is the service for? \\
\hline & $\begin{array}{l}\text { Who is involved in providing the } \\
\text { service? }\end{array}$ \\
\hline \multirow[t]{3}{*}{ Description of e-health service } & Purpose of the service \\
\hline & How service works? \\
\hline & How service is used? \\
\hline \multirow{3}{*}{$\begin{array}{l}\text { Description of test/evaluation } \\
\text { conducted }\end{array}$} & Test results \\
\hline & Level of job-fit \\
\hline & User and provider evaluation \\
\hline \multirow[t]{3}{*}{ Commercial use } & Is it in commercial use today? \\
\hline & Service length of use? \\
\hline & Track record? \\
\hline \multicolumn{2}{|l|}{ Advantages } \\
\hline Disadvantages & \\
\hline
\end{tabular}

(EDGE) capabilities, and third-generation (3G) mobile technology Universal Mobile Telecommunications System is mostly available at more densely populated urban regions.

Norway. Norway has almost full broadband coverage, with 99\% of Norwegian households having access to fixed broadband (almost $100 \%$ have access, including mobile broadband facilities). ${ }^{14}$ In the future, broadband services in Norway, for example, care for elderly via video conference, will require more broadband capacity. The Norwegian Health Net is the dedicated arena for electronic information and communication in the Norwegian health and social sector. The network is built using Internet technology with focus on information security, capacity, and availability. During the period of this study, all the public hospitals, 75\% of the general practitioners (GPs)' surgeries, and some private specialists were connected to the health network.

Scotland. In Scotland, work is continuing at a national level to develop robust telecommunication networks that can handle image and data transfer and routine video conferencing within the health service. ${ }^{15,16}$ Mobile phone network coverage and broadband access is not universal across northern peripheral areas of Scotland, and the Scottish Government claims that this is hindering the adoption of ehealth solutions. ${ }^{17}$ In the National Health Service (NHS) Highland (Scotland's largest remote and rural NHS Board), the Scottish research team reported that telecommunications performance was variable, with lower broadband speeds and capacity. Basic coverage in the remote and rural areas has been a recent telecommunications issue. ${ }^{17}$ Mobile connectivity is predominantly $2 \mathrm{G}$, but some remote and rural areas have less coverage. At the time of the study, $3 \mathrm{G}$ network coverage was available currently in the sole Highland city of Inverness. Telecommunications in the northern periphery areas of Scotland was generally more challenging than in Norway, Sweden, or Finland.

\section{E-HEALTH DEVELOPMENT}

The results from the mapping exercise highlighted that e-health development in the northern peripheral regions of these countries is also at differing stages. The wider e-health agenda of EPRs or the patient management systems is a prime example. The electronic health record (EHR) is now used in virtually all parts of the primary healthcare system in Sweden. ${ }^{9}$ In Norway, all 80 hospitals have an EHR but communication between hospitals and rural GPs is slower. ${ }^{18}$ In Finland, local health record systems are advanced, as all hospital districts and healthcare centers use EPRs almost exclusively; their use is also widespread in health centers and specialized care. ${ }^{2}$ Because of the fact that local medical records are already electronic, as a next step the regional exchange of patient data is used by $76 \%$ of hospitals and more than half of healthcare centers. A national EHR repository is planned for 2011. ${ }^{2}$ In Scotland, EPRs are in widespread use, and a "clinical portal" window is being developed, which will enable differing patient information systems to link together-this is not active in the northern periphery areas as yet but is part of the national plan. ${ }^{15}$

The radiology Picture Archiving and Communications System (PACS) designed to electronically store medical imaging is another ehealth example mapped across all four countries, albeit at differing stages of use. In Scotland, PACS is being rolled out at a national level across its 15 health boards (39 hospitals). NHS Highland PACS was in the process of being implemented (excluding the Argyll \& Bute area, which was testing the connectivity between sites). The national roll out in Scotland focuses on hospital sites and has undoubtedly improved communication between remote hospitals and district centers. GP access to radiological images is, however, yet to develop in Scotland. In Scotland's three partnering countries, the use of PACS was recorded to be widespread across hospitals and in primary healthcare centers.

Specific e-health applications were also identified by medical speciality during the mapping exercise. Here, we document the number of established e-health applications and summarize some key examples in each country. We also detail the clinical applications identified by medical speciality in the form of a table.

Sweden. Sweden identified 45 e-health services, with approximately half of these services using video-conferencing facilities. Examples 


\section{ROBERTS ET AL.}

include remote leg ulcer consultation, diagnosis and planning for patients with eye problems, radiology, dermatology, and remote physiotherapy from home, and digital technology used for the diagnosis of ear infections. Remote monitoring of physiological parameters is a recent innovation developed by Västerbotten County Council and a local company, Explizit. This service enables home monitoring of patients whose physiological parameters must be controlled continuously. Portable health monitoring equipment is used to take physiological measures including electrocardiogram, spirometry, pulse oximetry, and readings of pulse and blood pressure. The equipment is located in the patient's home and is very userfriendly. Healthcare professionals have access to the monitoring results at all times and are alerted if any of the monitored values are abnormal. By providing home monitoring of physiological parameters, doctors are able to make early and accurate diagnoses and provide close follow-ups, and thus, costly hospitalizations can be often avoided.

Remote speech therapy was also a demonstrable key e-health service provided by the North Sweden University Hospital to the county councils healthcare centers and is now part of the standard service provided to the patients. The service is aimed for patients who have problems with speech formulation. The diagnostic groups in this project include people who suffer from aphasia, dysphasia, Parkinson's disease, or dyslexia. Also included are children between 3 and 4 years of age who have been referred to child healthcare units for speech evaluation and adults who suffer from voice problems.

Finland. The Finnish research team identified 52 products/services during the geographical mapping exercise, achieving a 44\% response rate from commercial companies to their online questionnaire. Most of the companies were small or medium enterprises marketing either one or more products/services concept. The target user for the e-health solutions identified included a substantial mix of private sector, primary healthcare, specialized healthcare, public sector, well-being service providers, and citizens. Results identified that older people formed the largest customer group with special health needs, in addition to solutions for the follow-up of chronic diseases. Finland is ongoing in developing and testing versatile e-health services. Among one of the most advanced is the Oulu self-care information technology (IT) platform where people can have services via net application. This individual health record platform enables citizens to consult professionals, schedule appointments, download own measurement data, and see laboratory results. Such direct e-health services cover $\sim 2 \%-10 \%$ of service providers, but coverage is rapidly increasing. ${ }^{2}$

E-health concepts for the management of chronic diseases were also mapped in Finland, which included monitoring of diabetes, cholesterol, blood pressure, and weight control. Finland identified a range of types of e-health solutions including mobile phone systems such as the eHIT Ltd.'s mobile phone-based system for self-care.

Remote video consultations between primary and secondary healthcare centers were offered by $66 \%$ of hospitals and used by $17 \%$ of healthcare centers. ${ }^{2}$ Among them, telepsychiatric services in the northern part of the country are widespread.

Norway. The Norwegian research team mapped 32 e-health projects and services in the northern periphery regions of Norway, identifying a number of discipline-specific projects such as a tele-obstetric broadband service, including ultrasound; videoconferencing and cardiotocogram; telepsychiatry; videoconference-based emergency medicine; and eczema counseling over the Internet. A total of 12 key telemedicine services were described by the Norwegian team. Eleven of these services were offered between hospitals or from hospitals to GPs/ nurses. One service involved direct electronic communication between the GP and patient, where patients can e-mail questions to the GP and receive an e-mail response. Other telemedicine services include radiology, leg ulcers guidance between hospitals and nurses in home care using digital photographs, assessments for plastic surgery, ophthalmology, and otorhinolaryngology. In addition, a teledermatology service was offered by hospitals to GPs. The services offer educational opportunity to the participating GPs in the early phases.

Scotland. In the sparsely populated areas of Highland, the research team identified 19 active e-health projects, 7 of which were operating at national level, including information communication technology record systems such as the Emergency Care Summary, Scottish Care Information store and gateway, the teleradiology system PACS, and Web-based health information points such as NHS 24 (health information and self-care advice) online. A Telecare Development program, enabling home monitoring for the elderly and diabetes retinal screening, where digital images are stored on a national diabetes database, was also identified. In addition, a small number of managed clinical networks (a network of people involved in the care of a particular condition) to support information sharing around long-term conditions, such as diabetes and cancer, were found to be operating regionally-these included the North of Scotland Cancer Network and North of Scotland Epilepsy Network, both in the Highland region. Although formal evidence of teledermatology was not identified, it may be in use on an ad-hoc basis. E-health monitoring using mobile phone technology was not identified in the northern peripheral region of Scotland.

Within NHS Highland, local e-health applications were identified in the medical fields of ear, nose, and throat (ENT) endoscopy, cardiology, neurology, and pediatrics; examples include home monitoring of patients with heart failure after hospital discharge in Argyll $\&$ Bute, remote video consultations to support patients with complex epilepsy, and ENT endoscopy screening of the upper airway using a video conference link between Raigmore Hospital (in the city of Inverness) and the Western Isles Hospital in Stornoway. The use of video conferencing facilities was also identified amongst professionals for multidisciplinary team meetings in cancer and pathology between Raigmore (the main hospital) in NHS Highland and outlying remote hospitals.

Table 2 details the e-health applications identified during the mapping exercise, by clinical speciality. 


\begin{tabular}{|c|c|c|c|c|}
\hline & SCOTLAND & NORWAY & FINLAND & SWEDEN \\
\hline Cardiology & * & * & & * \\
\hline Dementia & & & & * \\
\hline Dermatology & & * & * & * \\
\hline Elderly monitoring & * & * & * & * \\
\hline ENT & * & * & & * \\
\hline Ophthalmology (including diabetes eye screening) & * & * & * & * \\
\hline General Practice & & * & * & \\
\hline Obstetrics & & * & & * \\
\hline Orthopedic & & * & * & * \\
\hline Pediatric & * & * & & * \\
\hline Pain monitoring & & & * & * \\
\hline Pathology & * & & * & * \\
\hline Surgery (including plastic surgery) & & * & * & * \\
\hline Physiotherapy & & & & * \\
\hline Radiology (including PACS) & * & * & * & * \\
\hline
\end{tabular}

Asterisks indicate where evidence of e-health innovation was detected (by medical specialty).

ENT, ear, nose, and throat; PACS, Picture Archiving and Communications System.

Across all four countries, there was an acknowledgment that the elderly and patients with chronic/long-term conditions are priority groups for e-health solutions development, and within this, the importance of prolonging independent living was identified.

\section{Discussion}

The overall aims of this article were to identify active e-health services in remote and rural areas of Sweden, Norway, Finland, and Scotland, to describe the supporting telecommunications infrastructure, and to document a portfolio of established e-health services. This mapping exercise, which identified 148 e-health applications, helps to identify the gaps in remote and rural e-health by highlighting where there are possibilities to develop/share established e-health solutions. In particular, examples in the management of chronic diseases, physiotherapy, speech therapy, and mental health were identified.

All four countries in this study demonstrated high-quality, established examples of e-health solutions. The northern peripheral regions included in this study all demonstrated enthusiasm about the advancement of e-health across sparsely populated areas of northern Europe and a commitment to e-health strategy.

Evidence suggests that Nordic countries have been at the forefront of some e-health developments such as administrative and data 


\section{ROBERTS ET AL.}

management systems. Results of this study demonstrated that the northern peripheral areas of Finland, Sweden, and Norway already have well-developed telecommunication systems, including extensive broadband and $3 \mathrm{G}$ mobile phone network coverage. This level of telecommunication infrastructure in the Highland region of Scotland was still developing during this research.

Results also indicated that clinical e-health solutions have developed at a variable pace across participating countries. E-health developments in Scotland were of a smaller scale. This may partially be explained by the Scottish policy approach to e-health development, which is to link IT systems together to communicate with a "simple bridge" rather than national IT redesign. ${ }^{8}$ It should also be noted that although some of the local projects identified in this study have not been implemented on a larger scale, they have, nevertheless, shown to be successful examples in their own right. Despite challenges, e-health is seen as integral to health service delivery in the remote rural regions of Scotland.

There were several limitations to this study. First, differences were apparent in the qualitative methods used during the mapping exercise. The methods used may not have captured all e-health innovations in the area. Second, inconsistencies in the types of e-health examples gathered were also identified. For example, the Norwegian research team chose to predominantly exclude EPRs, exchange of medical documents, and citizen health information and focused on clinical e-health applications, which were identified as most suitable examples for transfer. Third, the mapping exercise collected only information that was available and, therefore, did not necessarily address whether services were cost effective. The results of the overall study may address some of these questions.

Despite these limitations, this article is important in that it provides an international comparison of e-health. It is always challenging to compile comparable information across countries, languages, cultures, and healthcare systems. Therefore, this overview is a valuable addition to academic literature on e-health in northern Europe. This overview also provides knowledge sharing on e-health across the program area and has thus enabled the transfer of a number of solutions amongst the partners in this study. The overview has also contributed to improving and standardization of delivery of services across European Union (EU) member states.

\section{Conclusions}

This research has demonstrated that within the northern periphery areas of Scotland, Norway, Finland, and Sweden, there is range of innovative e-health applications applied at a national, local, or project level. All four countries currently share similarities in terms of geography and challenges to health services, although there are no shared policies to address these. One of the aims of the NPP is to encourage and support the transnational cooperation between regions of Europe. The study identified a variation in e-health infrastructure within the selected countries. There is clearly great potential for productive e-health solutions knowledge transfer amongst the partners in this study, with the recognition that the focus is on improved services for remote and rural patients.

\section{Acknowledgments}

The authors thank all those health service personnel who took the time to participate in the mapping exercise of the NPP Competitive Health Services project. The authors also thank all members of the Competitive Health Services project team in Finland, Sweden, Norway, Scotland, and Ireland and Mrs. Fiona Smith and Lee Dowie from the Centre for Rural Health, University of Aberdeen, for administrative support. In addition, the authors thank Christine McClusky at the Scottish Centre for Telehealth, for her input and guidance.

\section{Disclosure Statement}

No competing financial interests exist.

\section{REFERENCES}

1. The Northern Periphery Programme. Available at www.northernperiphery.net/ eligible-area-g.asp (last accessed April 20, 2010).

2. Hämäläinen $P$, Reponen J, Winblad I. eHealth of Finland, Check point 2008. National Institute for Health and Welfare Report 1/2009. Available at www.thl.fi/thl-client/pdfs/f5ca5a36-f2c6-4e94-ae95-a7b439b1169b (last accessed April 20, 2010).

3. Kautto M, Fritzell J, Hvinden B, Kvist J, Uusitalo H. Nordic welfare states in the European context. London: Routledge, 2006.

4. Cacioppo JT, Hughes ME, Waite $\sqcup$, Hawkley LC, Thisted RA. Loneliness as a specific risk factor of depressive symptoms: Cross-sectional and longitudinal analyses. Psychol Aging 2006;21:140-151.

5. Andreassen HK, et al. European citizens' use of E-health services: A study of seven countries. BMC Public Health 2007;7:53

6. Australian New Zealand TeleHealth Committee. TeleHealth Activities overseas, Factsheet 4. Proceedings of the teleHealth Think Tank. Melbourne, 2000. Available at www.health.gov.au/internet/hconnect/publishing.nsf/content/ 7746B10691FA666CCA257128007B7EAF/\$File/teleplan.pdf (last accessed April 20, 2010).

7. The Scottish Government. eHealth Strategy 2008-2011. Report. 2008. Available at www.scotland.gov.uk/Publications/2008/08/27103130/0 (last accessed April 20, 2010).

8. Norwegian Ministry of Health and Care Services: National Health Plan for Norway 2007-2010. Available at www.regjeringen.no/upload/HOD/ National\%20health\%20plan_eng_06052007.pdf (last accessed October 24, 2010).

9. The Government Office of Sweden. Ministry of health and Social Affairs. National strategy for eHealth. 2006. Available at www.sweden.gov.se/sb/d/574/ a/64324 (last accessed April 20, 2010).

10. Wikipedia. Available at http://en.wikipedia.org/wiki/EHealth (last accessed April 20, 2010)

11. Oh H, Rizo C, Enkin M, Jadad A. What is eHealth: A systematic review of published definitions. J Med Internet Res 2006;7:1.

12. Northern Periphery Programme 2007-2013. A portfolio of eHealth application in European sparsely populated areas. Available at www.ehealthservices.eul default (last accessed April 20, 2010).

13. Bredbandskartläggning. en geografisk översikt av infrastrukturen för bredband $\mathrm{i}$ Sverige. 2009. Post och Telestyreslsen PTS, Report No. PTS-ER-2009:8. 


\section{E-HEALTH COMPARISON IN THE NORTHERN PERIPHERY}

14. Ministry of Government Administration. Bredbånd 2.0-status og utvikling mot 2015. 2009. Available at www.regjeringen.no/en/dep/fad/dok/ rapporter_planer/rapporter/2009/bredband-20.html?id=570961 (last accessed April 20, 2010).

15. The Scottish Government. Better eHealth: Better Care. Available at www.ehealth.scot.nhs.uk/?page_id=224 (last accessed April 20, 2010).

16. Scottish Government. Delivering for remote and rural healthcare: The final report of the remote and rural workstream. Edinburgh, Scottish Government, 2008.

17. Highlands \& Islands Enterprise. Telecomms connectivity in the Highlands and Islands. Report 2009. Available at www.hie.co.uk/highlands-and-islands/ economic-reports-and-research/default.html?year = 2009 (last accessed October 24, 2010).

18. Heimly V. Standardization, innovation and the deployment of electronic referral software in Norway. J Telemed Telecare 2008;14:359-362.
Address correspondence to: Anne Roberts, B.A. (Hons) Centre for Rural Health

University of Aberdeen The Centre for Health Science Old Perth Road Inverness Iv2 3JH United Kingdom

E-mail: a.roberts@abdn.ac.uk; a.roberts@abdn.ac.uk

Received: May 14, 2010

Revised: July 14, 2010

Accepted: July 17, 2010 